\title{
Mechanical Properties of Thai Dendrocalamus Bamboo Column Joints
}

\author{
Sayan Kongsricharoen ${ }^{1}$ \\ ${ }^{* 1}$ A Ph.D. Student in the Engineering Law and Inspection \\ The program, Ramkhamhaeng University; \\ Asst. Prof. Dr. Waranon Kongsong ${ }^{2}$ \\ ${ }^{* 2}$ Assistant Professor in the Engineering Law and \\ Inspection \\ Faculty of Engineering, Ramkhamhaeng University \\ ORCID: 0000-0003-2651-8476
}

Asst. Prof. Dr. Sirawan Ruangchuay Tuprakay ${ }^{5}$

${ }^{*}$ Assistant Professor in Urban and Industry Environment Faculty of science and Technology, Suan Dusit University

\author{
Assoc. Prof. Dr. Seree Tuprakay ${ }^{3}$ \\ ${ }^{*}$ Associate Professor in the Engineering Law and \\ Inspection Program, Faculty of Engineering, \\ Ramkhamhaeng University. \\ Dr. Chaleeporn Thammapornram ${ }^{4}$ \\ ${ }^{*}$ Bamboo Research center Director, the Engineering Law \\ and Inspection Program, Faculty of Engineering \\ Ramkhamhaeng University \\ ORCID: 0000-0003-2273-5473 \\ Dr. Boontham Harnphanich ${ }^{6}$ \\ ${ }^{*}$ Special Lecturer in the Engineering Law and Inspection \\ Faculty of Engineering, Ramkhamhaeng University
}

\begin{abstract}
The Joint is considered an essential component in construction. In the paper, study the compressive strength tests of standard-sized of the Thai Dendrocalamus Giganteus bamboo laminated columns that connected in 3 different joints. The test results show that column type 3 joints can withstand the highest compressive strength of $12333 \mathrm{kgf}$. From the test results show that bamboo columns that are connected. The force is reduced by approximately 90 percent compared with the column without the joint.
\end{abstract}

Keywords-Dendrocalamus Gigantues; joint ; compressive strength

\section{INTRODUCTION}

Thai Dendrocalamuus Giganteus (TDG) Bamboo is the giant bamboo in Thailand that can grow anywhere around Thailand. TDG bamboo at age 3-years form Ta Wong $\mathrm{Pa}$ district of Nan province, cut from the bottom 6 meters long and divided into 3 parts ;bottom middle and top each part cut 2 meters long. The physical properties of the 3-year-old TDG bamboo, the test results as following by [1][2][3][4][5] can be summarized as follows

1. TDG bamboo at the bottom part with an average circumference of 48.64 centimeters and an average thickness of 2.86 centimeters.

2. TDG bamboo in the middle part of the bamboo with an average circumference of $43.42 \mathrm{~cm}$ and an average thickness of $1.43 \mathrm{~cm}$.

3. TDG bamboo in the top part of the bamboo with an average circumference of $39.27 \mathrm{~cm}$ and an average thickness of bamboo of $0.97 \mathrm{~cm}$.

TDG bamboo laminated have been studied by [6][7][8] the analysis of the mechanical properties; compressive strength, bending and shear according to the test by ASTMD 143-09 [9] and DPT 1221-51 [10] the test results can be summarized as follows

A. Compressive strength of TDG laminated column

TDG bamboo laminated column for this paper study the factor of temperature and moisture that affect the compressive strength. [7] The compressive strength of bamboo column size standard $50 \times 50 \times 200 \mathrm{~mm}$ total 3 pieces test the factor that affects the compressive strength in 2 cases; sink in the water for 48 hours. The results of the test shown that TDG column got the water absorption very slow, as shown in table 1. MA2 code for the specimens without a soak in the water with moisture content $7 \%$ compared with the MA1 sink in the water 24 hours the moisture content to $21.20 \%$ and MA3 sink the water 48 hours with the moisture content $26.30 \%$. For this study, the results of the increased moisture content affect the load properties because of the failure of the adhesion. Another case study of temperature affects the bearing capacity of bamboo poles; found that the temperature at 0 degrees Celsius and 60 degrees Celsius is not very different. Then shows that the change of temperature does not affect the strength of bamboo. The study found that TDG bamboo laminated column can be classified as a hardwood.

Table 1. Average of the test result of TDG bamboo laminated column

\begin{tabular}{cccccc}
\hline \multirow{2}{*}{ Type } & Weight & Density & Moisture & Load & Stress \\
\cline { 2 - 6 } & $\mathbf{g}$ & $\mathbf{g} / \mathbf{c m}^{\mathbf{3}}$ & $\boldsymbol{\%}$ & $\mathbf{k g f}$ & $\mathbf{k g} / \mathbf{c m}^{2}$ \\
\hline MA1 & 299 & 0.60 & 21.20 & 13450.00 & 538.00 \\
MA2 & 336 & 0.67 & 7.10 & 15479.57 & 619.18 \\
MA3 & 335 & 0.67 & 26.30 & 13950.00 & 558.00 \\
\hline
\end{tabular}

\section{B. Shear strength of TDG laminated column}

The mechanical properties of bamboo are based on ASTM D143-09 and Standard for the wood test in Thailand (DPT 1221-51).[11] The details of the specimen's size $63 \times 50 \times 50 \mathrm{~mm}$ with a different part of bamboo the results as shown in table 2 the best results shown that TDG bamboo laminate at the bottom part can handle the best load and classified as a hardwood 
Table 2. Average of the test result of TDG bamboo laminated column

\begin{tabular}{cccccc}
\hline \multirow{2}{*}{ Type } & Weight & Density & Moisture & Load & Stress \\
\cline { 2 - 6 } & $\mathbf{g}$ & d $^{\prime} / \mathbf{c m}^{\mathbf{3}}$ & \% & $\mathbf{k g f}$ & $\mathbf{k g} / \mathbf{c m}^{2}$ \\
\hline TOP & 99.50 & 0.69 & 9.07 & 1319.30 & 52.77 \\
Middle & 95.50 & 0.66 & 9.60 & 1385.76 & 55.43 \\
Bottom & 87.33 & 0.60 & 9.20 & 2504.26 & 100.17 \\
\hline
\end{tabular}

\section{Bending strength of TDG laminated column}

The bending strength of TDG laminated [12] tested with the size standard; found that the TDG beam-type NFR and FR fit in the categories of the hardwood. Average of the modulus of elasticity; TDG beam coated with resin $270140.87 \mathrm{~kg} / \mathrm{cm}^{2}$, TDG beam without coated with resin $159457.74 \mathrm{~kg} / \mathrm{cm}^{2}$. TDG bamboo beam classified as a hardwood. From the study of mechanical properties of processed TDG bamboo, found that bamboo can be used to replace wood in the future. Therefore, this research studied the joint of structural bamboo columns. So that TDG bamboo can be used widely.

\section{RESEARCH OBJECTIVES}

The scope of a study; TDG bamboo used for experimental taken from Tha Wang Pha district of Nan province, at age 3 years. The TDG culms measured above 6 meters from the bottom culms and cut into 2 meters long set the code to 3 part; bottom middle and top. In this paper, the TDG bamboo laminated column made from the bottom part. The design of the TDG column lay with horizontal fiber as shown in fig 1 .

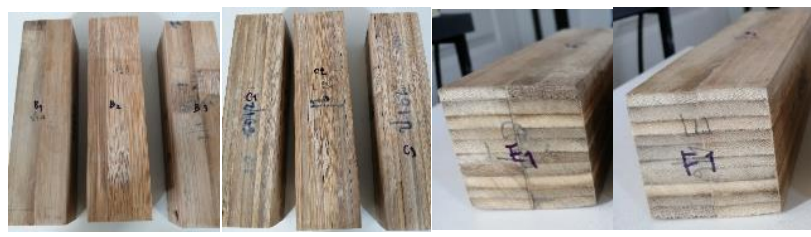

Fig 1 the TDG bamboo column laminated design

\section{MATERIALS AND METHODS}

In this study, TDG bamboo aged 3 years immersed in water for 10 days and dry them with the solar kiln house 1-2 months. After the bamboo turns into yellow color, cut the bamboo to make the strip as shown in fig. 2 the size of the strip width 3 $\mathrm{cm}$ and long 2 meters.
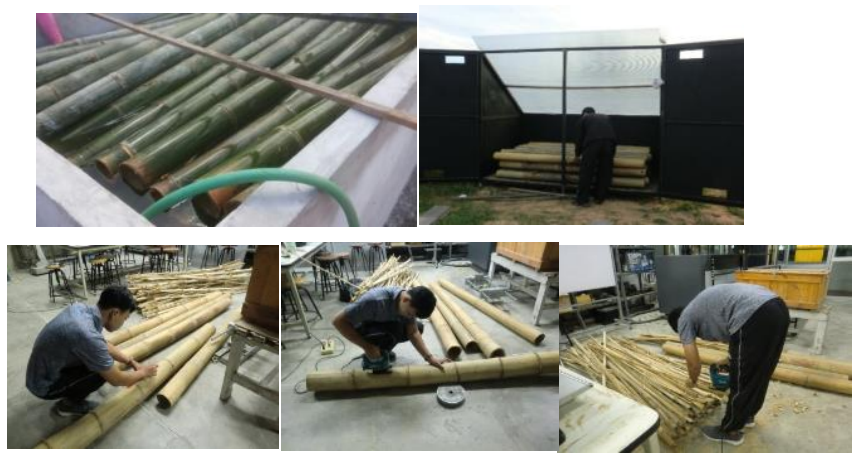

Fig. 2 the strips making the process
The stripping process takes approximate 3 months and checks for moisture content in the strip, not over $12 \%$ [13].The following processes are essential as follows.

\section{A. TDG bamboo laminated column forming process}

The strips from the bottom part are glued together to the size standard $50 \times 50 \times 200 \mathrm{~mm}$. The strip glue and clamp for more than 8 hours after that cut to size, as shown in fig 3 .

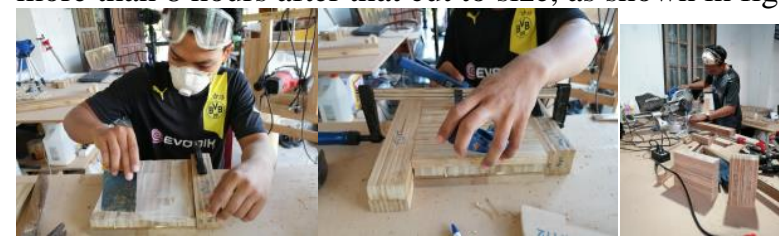

Fig. 3 Column forming process

All the specimens after glue let them dry for 1 month before testing the mechanical properties. To allow the glue to dry and complete adhesion.In this paper, Most of the production processes are manual production and general woodworking tools

\section{B. TDG bamboo laminated Joint making process}

The joints in the paper design in 3 types. The pattern of the joint design in the paper and draw in the TDG column after that cut to size with a jigsaw along with the pattern as shown in fig 4 .

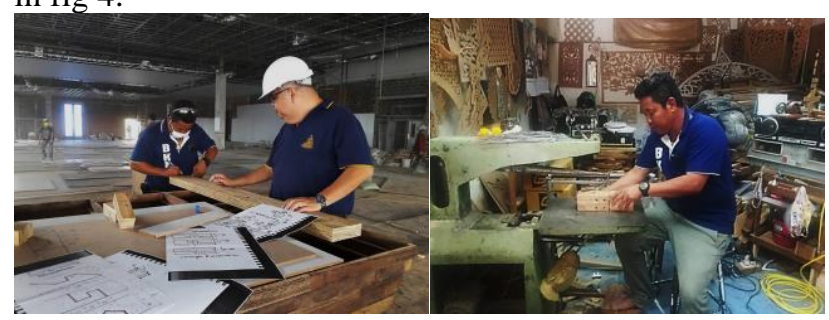

Fig. 4 Joint making process

\section{Joint type}

The specimens forming for compression test of the TDG laminated bamboo according to DYP 1221-51.Three types of joint with a total of 3 pieces of each type.The total of the specimens 12 pieces. The TDG joint design as shown in fig 5.

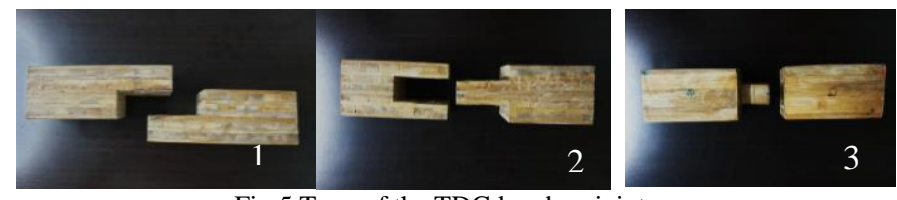

Fig.5 Type of the TDG bamboo joints

The fig 5 the TDG bamboo laminated columns which joint in three different types as follows

1. Lap joint the bamboo column cut and joint half and a half straight. Code this joint as type 1

2. Tongue and Groove joint which joint half and code this common type 2 .

3. Mortise \& Tenon joint which joint half and code this common type 3 .

\section{TESTING AND TESTING STANDARD}

The mechanical properties of bamboo are based on ASTM D143-09 and Standard for the wood test in Thailand (DTP 1222-51) [14]. The compressive test setting, as shown in fig 6 with the Universal test machine. 


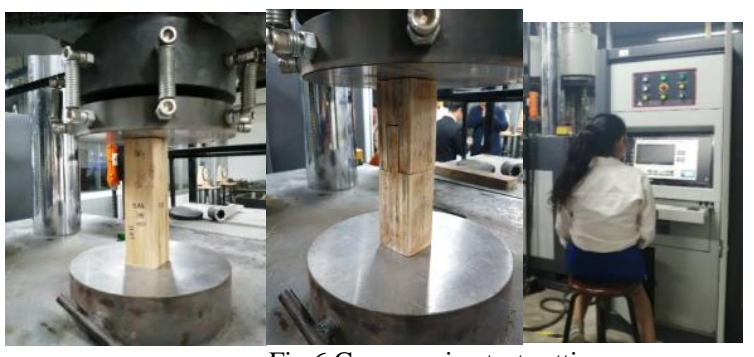

Fig.6 Compressive test setting

\section{EXPERIMENT RESULTS AND DISCUSSION}

The specimen's results analysis with computer software. The test results analysis as the following;

A. The test results of the joints Type 1

The lap - joint of the TDG bamboo column laminates without the joint code BNJ with density 0.58 $\mathrm{g} / \mathrm{cm}^{3}$ with moisture, $9.40 \%$ can resist the load $12,604.03 \mathrm{kgf}$ with the stress $504.16 \mathrm{~kg} / \mathrm{cm}^{2}$. The average best result of the column with joints code BA2 can resist the load $12162.89 \mathrm{kgf}$ with the stress $486.52 \mathrm{~kg} / \mathrm{cm}^{2}$. The average test results as shown in table 3

Table 3. The average test of the joints type 1

\begin{tabular}{cccccc}
\hline \multirow{2}{*}{ Type } & Weight & Density & Moisture & Load & Stress \\
\cline { 2 - 5 } & $\mathbf{g}$ & $\mathbf{d}^{\prime} \mathrm{cm}^{\mathbf{3}}$ & $\mathbf{\%}$ & $\mathbf{k g f}$ & $\mathbf{k g} / \mathbf{c m}^{\mathbf{2}}$ \\
\hline BNJ & 292 & 0.58 & 9.40 & 12604.03 & 504.16 \\
BA1 & 303 & 0.61 & 7.60 & 11658.73 & 466.35 \\
BA2 & 292 & 0.58 & 9.40 & 12162.89 & 486.52 \\
BA3 & 299 & 0.60 & 6.90 & 11973.83 & 478.95 \\
\hline
\end{tabular}

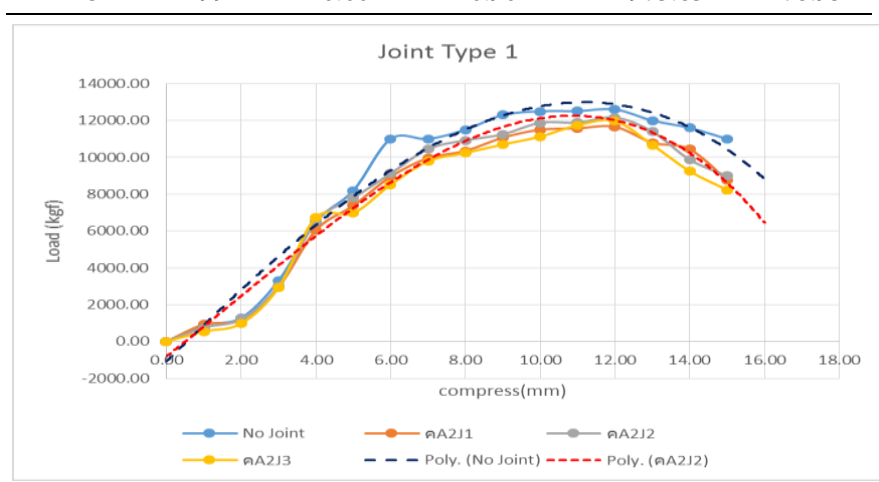

Fig.7 Compressive test joint Type 1

The failure of the bamboo column joint type 1 (Lap joint) as shown in fig 8 the joint failure with splitting type along the glue line but the specimens still in good condition not broken as shown in fig 8

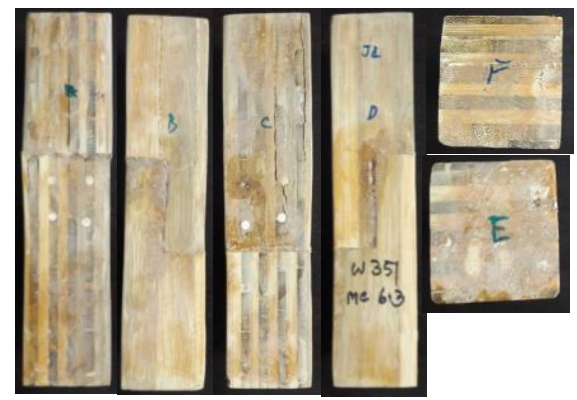

Fig. 8 The failure of the bamboo column joints type 1

\section{B. The test results of the joints type 2}

The Tongue and Groove joint of the TDG bamboo column laminates without the joint which the code $\mathrm{BNJ}$; density 0.60 g $/ \mathrm{Cm}^{3}$ and moisture $6.90 \%$ can resist the load $12,444.30 \mathrm{kgf}$ and the stress $497.77 \mathrm{~kg} / \mathrm{cm}^{2}$.The average best result of the column with joints code BA2 can resist the load 12,379.95 kgf with the stress $495.20 \mathrm{~kg} / \mathrm{cm}^{2}$. The average results as shown in table 4 and fig 9

Table 4. The average test of the joints type 2

\begin{tabular}{cccccc}
\hline \multirow{2}{*}{ Type } & Weight & Density & Moisture & Load & Stress \\
\cline { 2 - 6 } & $\mathbf{g}$ & g/cm $^{\mathbf{3}}$ & $\boldsymbol{\%}$ & $\mathbf{k g f}$ & $\mathbf{k g} / \mathbf{c m}^{\mathbf{2}}$ \\
\hline BNJ & 299 & 0.60 & 6.90 & 12444.30 & 497.77 \\
BA1 & 299 & 0.60 & 6.90 & 10004.00 & 400.16 \\
BA2 & 314 & 0.63 & 7.20 & 12379.95 & 495.20 \\
BA3 & 326 & 0.65 & 8.30 & 10629.25 & 440.18 \\
\hline
\end{tabular}

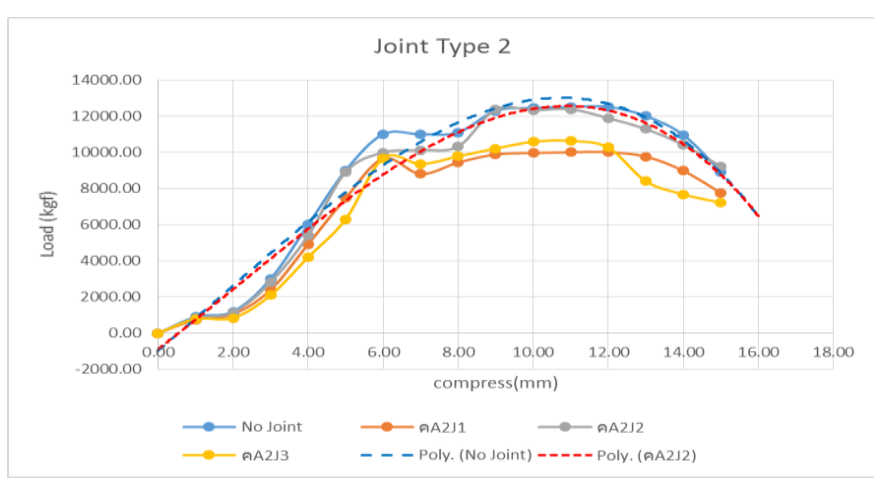

Fig.9 Compressive test joints type 2

The failure of the bamboo column joints type 2 (Tongue and Groove joint), as shown in fig 10 the joint failure with splitting type along the glue line; on the elevation $\mathrm{F}$ the splitting line across.

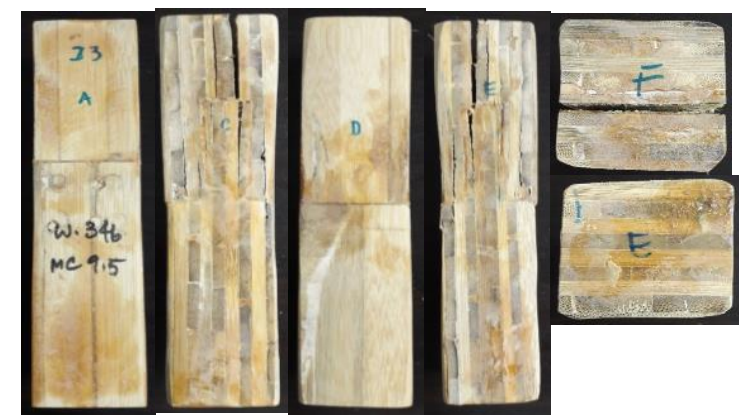

Fig.10 The failure of the bamboo column joints type 2

\section{The test results of the joints type 3}

Mortise \& Tenon joint of the TDG bamboo column laminates without the joint code BNJ with density $0.61 \mathrm{~g}^{\mathrm{cm}} \mathrm{cm}^{3}$ with moisture, $6.90 \%$ can resist the load $11,100 \mathrm{kgf}$ with the stress $444 \mathrm{~kg} / \mathrm{cm}^{2}$. The average best result of the column with joints code BA2 can resist the load $12162.89 \mathrm{kgf}$ with the stress $486.52 \mathrm{~kg} / \mathrm{cm}^{2}$. The average results as shown in table 5 and fig 11. 
Table 5. The average test of the joints type 3

\begin{tabular}{cccccc}
\hline \multirow{2}{*}{ Type } & Weight & Density & Moisture & Load & Stress \\
\cline { 2 - 6 } & $\mathbf{g}$ & g/cm $^{\mathbf{3}}$ & $\mathbf{\%}$ & $\mathbf{~ k g f}$ & $\mathbf{k g} / \mathbf{c m}^{\mathbf{2}}$ \\
\hline BNJ & 303 & 0.61 & 6.90 & 11100.00 & 444.00 \\
BA1 & 303 & 0.61 & 5.70 & 10245.85 & 409.83 \\
BA2 & 296 & 0.59 & 7.60 & 10692.25 & 427.69 \\
BA3 & 317 & 0.63 & 8.30 & 9566.75 & 382.67 \\
\hline
\end{tabular}

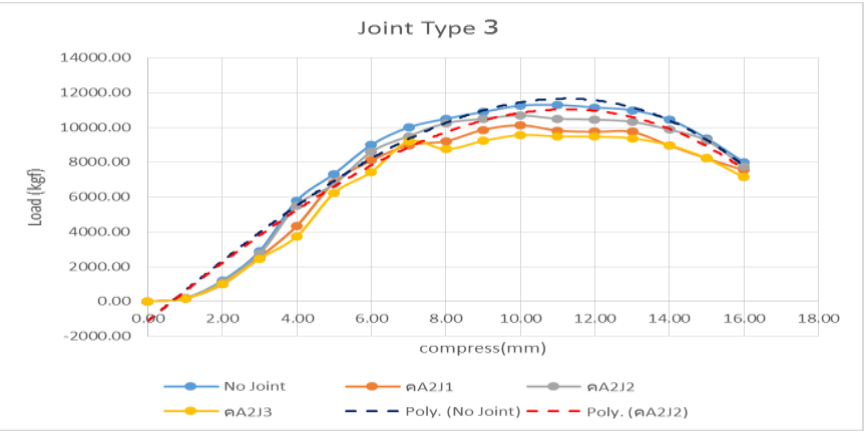

Fig.11 Compressive test joints type 3

The failure of the bamboo column joints type 3 (Lap joint) as shown in fig 9 the joint failure with splitting type along the glue line but the specimens still in good condition not broken as shown in fig 12

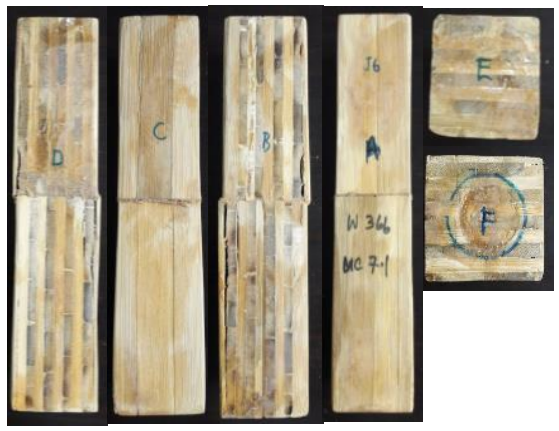

Fig.12 The failure of the bamboo column joints type 3

\section{Comparison of test results of joints}

From the test results of three types of joints type 1, the capacity load range between 93- $97 \%$. Type 2 the capacity load range between 80-99 \% .Type 3 the capacity load range between 86-96. The percent of the load, as shown in fig 13.The maximum load of TDG column joint approximate 12,379.95 kgf. The lowest load TDG column joint approximate 10004 kgf as shown in fig 14

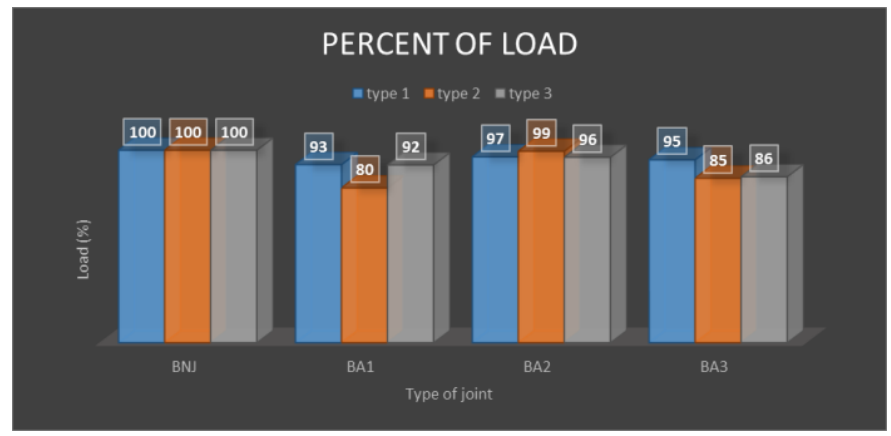

Fig.13 Comparison of load-capacity of bamboo column joint

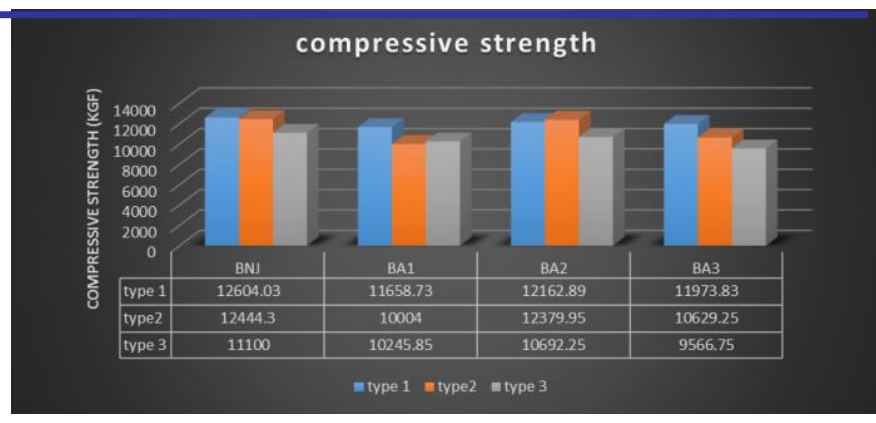

Fig. 14 Compressive strength of the TDG bamboo laminated' joint

\section{CONCLUSION}

From the test of the joint in a TDG bamboo column, found that the capacity compressive strength load average approximate 93 percent compared to the bamboo column without the joint. The bamboo column with the joint, much calculated the reduction load for safety. The compressive stress of the bamboo without the joint $500.48 \mathrm{~kg} / \mathrm{cm}^{2}$ and the worst compressive stress of the bamboo with the joint 400.16 $\mathrm{kg} / \mathrm{cm}^{2}$ so the safety factor equal

$$
\mathrm{FSC}=\frac{\sigma_{\mathrm{P}}}{\sigma_{\mathrm{J}}}=500.48 / 400.16=1.25
$$

However, the strength of the joint also depends on other factors such as the meticulousness of the process to make the joints, the time to let the glue dry as well as type of glue used in production.

\section{REFERENCES}

[1] Thammapornram C, (2018). The Innovation of Dendrocalamus Giganteus bamboo beam, Phd.dissertation of Engineering Law and Inspection: Faculty of Engineering Ramkhamhaeng University

[2] Thamapornram C, Kongsong, \& Buranakarn V (2018) .Thai Dendrocalamus Giganteus .Science, Technology, and Architecture. ESTCON Thailand

[3] Kongsricharoen, S., Kongsong, W., Tuprakay, S., Tuprakay, S., \& Thammapornram, C. (2019). Analysis the shear strength of Thai Dendrocalamus Gigantues (TDG) lamented bamboo by the factor of glue and location of the strips. International Journal of Civil Engineering and Technology (IJCIET), 253-262ASTM D143-09. (2009). Standard test method for small clear specimens of timber. West Conshohocken ,PA,USA: ASTM international

[4] Kongsricharoen, S., Kongsong, W., Tuprakay, S., Tuprakay, S., \& Thammapornram, C. (2019). Analysis the shear strength of Thai Dendrocalamus Gigantues (TDG) lamented bamboo by the factor of glue and location of the strips. International Journal of Civil Engineering and Technology (IJCIET), 253-262.

[5] Chaleeporn Thammapornram, Waranon Kongsong,Vorasun Buranakarn,effecting Factors of mechanical Properties of Tha Denrocalamus Gigantues Bamboo,International Journal of Civil Engineering and Technology (IJCIET) 9(13),2018,pp. 1457-1467

[6] Kongsricharean Songkarn, (2019). The Innovation of Dendrocalamus Giganteus bamboo Column, PhD.dissertation of Engineering Law and Inspection: Faculty of Engineering Ramkhamhaeng University

[7] Kongsricharean Sayan, (2019). The innovation of Thai Dendrocalamus giganteus bamboo joints according to building control Act and safety standard, PhD.dissertation of Engineering Law and Inspection: Faculty of Engineering Ramkhamhaeng University

[8] Thammapornram, C. (2019, January 16). Megabamtech1212. Retrieved from megabamtech1212: http://megabamtech1212.com/elementor1376/

[9] ASTM D143-09. (2009). Standard test method for small clear specimen of timber. West Conshohocken ,PA,USA: ASTM international

[10] DPT 1221-51. (2551). Standards Test of wood. Thailand: The Bureau of Building Inspection and Control Department of Public Works and Town \& Country planning 
[11] DPT 1226-51. (2551). Standards Test Method for shear test of wood parallel to Grain. Thailand: The Bureau of Building Inspection and Control Department of Public Works and Town \& Country planning

[12] DPT 1224-51. (2551). Standards Test for bending test of wood. Thailand: The Bureau of Building Inspection and Control Department of Public Works and Town \& Country planning

[13] DPT 1223-51. (2551). Standards Test for moisture content of wood. Thailand: The Bureau of Building Inspection and Control Department of Public Works and Town \& Country planning

[14] DPT 1222-51. (2551). Standards Test for compressive strength of wood. Thailand: The Bureau of Building Inspection and Control Department of Public Works and Town \& Country planning 